\title{
APPLYING THE MSHARPP METHOD IN RISK ASSESSMENT FOR THE WATER SUPPLY CRITICAL INFRASTRUCTURE SECTOR
}

\author{
Dorel BADEA* \\ dorel.badea@yahoo.com \\ Dumitru IANCU* \\ dorin_dan@yahoo.com \\ Olga Maria Cristina BUCOVETCHI** \\ olga.bucovetchi@upb.ro \\ * "NICOLAE BăLCESCU" LAND FoRCES ACADEMY, SibIU, ROMANIA \\ **UNIVERSITY POLITEHNICA OF BUCHAREST, ROMANIA
}

\begin{abstract}
The paper highlights a manner to assess risks for an important sector of critical infrastructure, that of water supply, frequently regulated in international legal systems. We took into consideration the fact that risk is a problem related to the processes of decision making under conditions of uncertainty in most cases, so that by this approach we bring to the attention of critical infrastructure managers, drawing on their experience, a simple method that can be considered in a preliminary stage of risk assessment specific to water supply.
\end{abstract}

\section{Keywords}

Risk, criticality, water supply

1. The Fundamental Elements of Risk Approach

Although standards in the field clearly provide the essential working vocabulary in risk management, there are still different approaches, more or less justified, on commonly used terminology, and hence the meaning of concepts. In this context, we must necessarily underline the specific difference between risk and vulnerability which arises from the fact that risk refers to threats (origins/causes), characterizing the consequences of their manifestation (loss, damage, suffering), the perception on the importance of consequences and the likelihood of manifestation of threats, while vulnerability relates to the subject / subjects of the exposure to threats manifestation, 
characterizing the type and level of susceptibility, the reaction to stress of the subject, to withstand the exposure to the manifestation of threats [1].

Analysis of the risks pertaining to critical infrastructure is therefore connected with the general problem of decision making under conditions of uncertainty. The risks do not exist on an obviously objective manner, but are "built" by the decision makers, while the parties involved in the decision-making process, possibly non participants in the process but targets of the effects thereof, could perceive this phenomenon as a threat.

Of all the methodologies and techniques of risk assessment, the qualitative analysis involves the use of qualitative criteria, using different categories for the separation of parameters using qualitative scales for each category. Also, qualitative decisions are made based on the experience of the assessor with the aim of assigning elements into categories. This type of approach (CARVER, MSHARPP) is a subjective one, but enables a higher degree of generalization, being less restrictive.

\section{Arguments for the Criticality of the Field}

People, nature and also economicindustrial activities need access to good quality water. In order to produce energy and food and to manufacture the goods that we need every day vast amounts of water are required. Let us also recall that among the first lessons studied in Natural Sciences we became aware of how long we can live without water!

In another analysis registry in the system of connections and relationships between different infrastructures, the water - energy interdependence is multifaceted. Energy production can affect water quality, but energy is essential to public water supply (water treatment) and the reduction of pollution through wastewater treatment. Hydro power plays an important and stable role in providing large and secure amounts of "green" energy.
It is estimated [2] that by 2015, only for developing countries 103 billion USD/year are required to finance water supply, sewerage and wastewater treatment. Also in 2011, 768 million people were deprived of controlled sources of drinking water, and 2.5 billion lacked decent sanitation.

$\mathrm{Al}$ a national level [3], according to the data available in 2013, Romania's total freshwater resources were estimated at about $212 \mathrm{Km}^{3} /$ year, of which 1844 million cubic meters in natural reservoirs and 7611 million Cubic meters in anthropic lakes (artificial), meaning a total of about $10 \mathrm{~km}^{3}$ of water stored. In a global context, the freshwater resources in Romania are placed at an average level being estimated between 201-500 Km 3 /year, or between 5.000-10.000 $\mathrm{m}^{3}$ per capita. Also, Romania is located within the European region where the physical scarcity of water is reduced (in 2007 Romania fell within the category of $6.000-15.000 \mathrm{~m}^{3} /$ capita). The same source mentions the fact that in 2050 , our country does not fall under the risk of depletion of water resources, the estimation on the annual amount available being higher than 1.7 million liters/capita.

According to the National Handbook for Water and Sanitation Operators, drafted by the competent Romanian Ministry, assessing criticality within a water and sanitation system means analyzing for each asset or group of assets the following issues: what happens if the asset crashes; what the chances are that it crashes; if the asset crashes, how many beneficiaries are affected; if the asset crashes what would be the repair costs; if the asset crashes, what other assets might be damaged; if the asset crashes, what are the consequences on the environment and human health. Criticality analysis has several important roles including that it allows the regional operator to manage risks and helps establish a more efficient way of allocating funds for rehabilitation and replacement [4]. 


\section{Technical Considerations on Water Supply}

The public water supply or sewerage network is part of the public water supply system, sewage system respectively, made up of the pipeline network, valves and additional buildings which ensure water distribution, takeover, disposal and transport of sewage water to/from two or more independent users, respectively from two or more individuals who live in individual houses or from two or more legal entities administering one single condominium, as it is defined by the law.

The biggest problems that the field of water supply is facing today, are due, in particular, to [5]:

- the exponential growth of water demand;

- the limited water resources and their uneven distribution, which requires large and expensive works of water accumulation and earthworks;

- the deterioration in the quality of water sources as a result of human activity and the emergence of industries which discharge waste containing highly stable impure substances, difficult to remove from the water within the purification or water treatment processes;

- the increase in standards on quality conditions that water delivered to the population must comply with.

The components of a water supply network (Figure no. 1), as well as those of a sewage network are usually located on public domain; where technical and economic conditions are favorable public network water supply or sewage may be located, with the consent of the owner, also on private land.

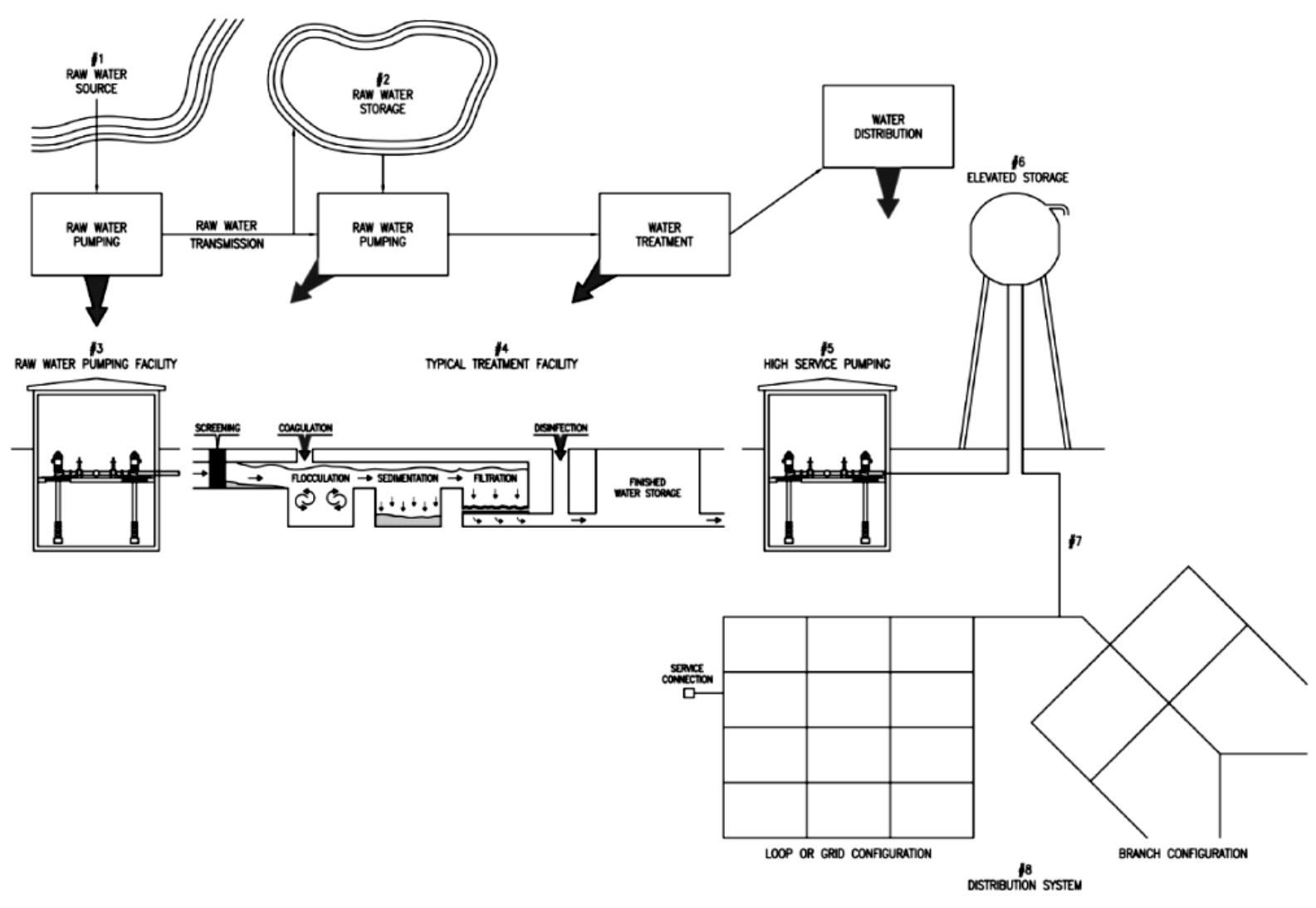

Figure no. 1: The structure of a typical municipal water station [6] 
The public drinking water supply system includes the ensemble of buildings and lands, technological installations, functional equipment and specific facilities, which ensure the public drinking water supply service. The public drinking water supply system usually contains the following components [7]: dams, culverts, raw water treatment plants, pumping stations, with or without pump, water storage tanks, distribution networks and connections to the point of demarcation.

\section{Applying the MSHARPP Method}

The MSHARPP analysis aims to measure threats to a target of particular importance in terms of the infrastructure holder, depending on the extent of the criteria that make up the acronym ( $\mathrm{M}$ - mission; $\mathrm{S}$ - symbolism; $\mathrm{H}$ - history; $\mathrm{A}$ - accessibility; $\mathrm{R}$ - recognizability; $\mathrm{P}$ - population; $\mathrm{P}$ - proximity). Each criterion is assigned a value of one to five, five being the higher level of vulnerability and one the lowest level of vulnerability. In analyzing the criteria the following significance of values is used (grades from one to five): [8], [9]

- the destruction or activity disruption of the objective has no effect on its ability to fulfill its mission (1);

- the objective can continue its mission if attacked, but with a lower yield (2);

- the objective operates at half of its maximum capacity, as a result of an attack (3);

- the objective's ability to fulfill its mission is largely hindered (4);
- the objective can not continue its mission (5).

In a possible scenario, risk assessment of a town/county water company by applying this method brings attention to the following applicative aspects:

- the mission is to serve under optimal conditions the population, businesses and public institutions in the respective company's operating area;

- the symbolism refers to the fact that the organization can be the main provider of drinking and household water in the county;

- the history points out that the water sector is not a major focus of the attacks, but it can be exploited if it presents major vulnerabilities;

- accessibility shows a low level of security and the company headquarters is most often located near a communication means;

- recognizability indicates an easy location with the help of maps and the internet, distinctive signs to identify the nature of the objective are present;

- population has the characteristic of a small number of employees who have a low exposure to external threats.

- proximity is assessed by the fact that the objective is located at about 1-3 kilometers from the residence town and in its vicinity there are no other buildings.

Summarizing these considerations, based on the significance of values allocation, the matrix below is obtained.

Table no. 1

Application of the method for a water supply system

\begin{tabular}{|l|c|c|c|c|c|c|c|c|}
\hline \multicolumn{1}{|c|}{ Objective } & M & S & H & A & $\mathbf{R}$ & $\mathbf{P}$ & $\mathbf{P}$ & Total \\
\hline Sewage networks & 2 & 1 & 1 & 4 & 5 & 5 & 3 & 21 \\
\hline Raw water pumping station & 3 & 1 & 1 & 2 & 4 & 3 & 1 & 15 \\
\hline Flocculation basin & 2 & 1 & 1 & 2 & 3 & 3 & 2 & 14 \\
\hline Sedimentation basin & 3 & 1 & 1 & 2 & 3 & 3 & 2 & 15 \\
\hline Water purification basin & 5 & 1 & 1 & 2 & 3 & 3 & 2 & 17 \\
\hline Disinfection basin & 1 & 1 & 1 & 2 & 3 & 3 & 2 & 13 \\
\hline Finished water basin & 3 & 1 & 3 & 3 & 3 & 3 & 2 & 18 \\
\hline Distribution network & 5 & 1 & 3 & 2 & 5 & 5 & 3 & 26 \\
\hline
\end{tabular}


Following the MSHARPP analysis for the case considered, we note that the increased vulnerability lies within the distribution network, due to its vital importance in carrying out the mission of population water supply and the population affected by its malfunctioning.

\section{Conclusions}

In the risk management of critical infrastructure, ideally would be to combine quantitative and qualitative methods, supported by efficient software through which to be able to check a wide range of scenarios having as foundation the idea "what would happen if..." and, subsequently, drafting the most adequate strategies regarding the technical, systemic and operational components of water supply infrastructure. Given the upward trend of urban demographic indicators and the role of water supply, it is desirable to ensure a high level of scalability (sector requirements will become ever more elevated).

\section{References}

1. O.M.C. Bucoveţchi, Critical Infrastructure Protection - Object - Based Modeling, (doctoral thesis developed and sustained in 2014 within the University Politehnica of Bucharest).

2. http://www.unwater.org/worldwaterday/campaign-materials/facts-and-figures/en

3. PromoSan - CRSPB, Analysis of the WWD 2013 Situation.

4. http://www.apabotosani.ro/Lists/Anunuri/Attachments/115/WUM RO FINAL.pdf

5. D. Soare, Optimization in the Operation of Water Supply Systems and Subsystems in their Structure from an Energetic Point of View, (doctoral thesis summary, University of Oradea, 2013), available at https://www.uoradea.ro/display1404

6. http://www.sswm.info/content/network-design-and-dimensioning

7. http://www.apacansb.ro/p.php?pag=definitii

8. www.iscwest.com/RNA ISCWest v2/docs

9. https://hainessecuritysolutions.com 